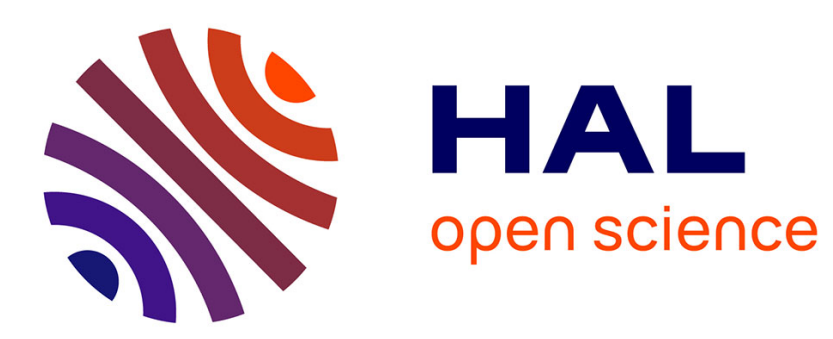

\title{
STACKING FAULT ENERGY CALCULATIONS IN THE FLUORITE STRUCTURE
}

\author{
R. Gaboriaud, M. Boisson, J. Grilhé
}

\section{To cite this version:}

R. Gaboriaud, M. Boisson, J. Grilhé. STACKING FAULT ENERGY CALCULATIONS IN THE FLUORITE STRUCTURE. Journal de Physique Colloques, 1976, 37 (C7), pp.C7-582-C7-585. 10.1051/jphyscol:19767135 . jpa-00216859

\section{HAL Id: jpa-00216859 https://hal.science/jpa-00216859}

Submitted on 1 Jan 1976

HAL is a multi-disciplinary open access archive for the deposit and dissemination of scientific research documents, whether they are published or not. The documents may come from teaching and research institutions in France or abroad, or from public or private research centers.
L'archive ouverte pluridisciplinaire HAL, est destinée au dépôt et à la diffusion de documents scientifiques de niveau recherche, publiés ou non, émanant des établissements d'enseignement et de recherche français ou étrangers, des laboratoires publics ou privés. 


\title{
STACKING FAULT ENERGY CALCULATIONS IN THE FLUORITE STRUCTURE
}

\author{
R. J. GABORIAUD, M. BOISSON, J. GRILHE
}

Laboratoire de Métallurgie Physique Faculté des Sciences, 40, avenue du Recteur-Pineau, 86022 Poitiers, France

\begin{abstract}
Résumé. - Des calculs d'énergies de faute d'empilement ont été effectués dans la structure fluorine. Plusieurs méthodes sont développées dans lesquelles différents potentiels à courte portée sont utilisés.

La contribution de la polarisation électronique est introduite par l'emploi d'un modèle de la coquille.

Il est montré que l'énergie de polarisation électronique est faible quand les fautes d'empilement sont relaxées. Les résultats obtenus par différentes méthodes sont comparés. Généralement, les énergies de faute d'empilement trouvées sont fortes.

Abstract. - Computer calculations of stacking fault energies have been carried out in ionic crystals having the fluorite structure.

Several methods are developped in which different short range potentials are used. In order to include the polarization a shell model is introduced.

It is shown that the polarization energy is low when the stacking faults are relaxed. The results obtained by the different methods are compared.

Generally, the stacking faults are found high.
\end{abstract}

1. Introduction. - Owing to the difficulty in obtaining experimental stacking fault energy (S. F. E.) data, in ionic crystals, theoretical S. F. E. calculations are therefore an interesting way to obtain this parameter.

The most recent planar defect calculations have generally been based on Born model of ionic solids $[1,2$, 3]. The crystal is simulated by ions of integral or effective charge between which a long range coulombic interaction takes place which is balanced by both a short range interaction resulting from the electronic cloud overlap and a polarization term as a consequence of the ion deformation.

Hitherto, calculations of S. F. E. in ionic crystals containing two species of ions, have been confined almost exclusively to the alkali halides. Nevertheless, materials having the fluorite structure are numerous and experimental or theoretical data are now available. Furthermore, interest in the fluorite structure is stimulated by the important practical applications of such materials as $\mathrm{UO}_{2}, \mathrm{PuO}_{2}, \mathrm{ThO}_{2}$, etc...

Owing to the strong ionic character of $\mathrm{CaF}_{2}$, a theoretical study of S. F. E. in the different crystallographic planes of this material is carried out in terms of pair potential interactions. The (110) planes of this structure being neutral (stoechiometric ratio $\mathrm{F} / \mathrm{Ca}=2$ ), the summation of the Madelung interactions allows a relaxation perpendicular to the defect plane [1]. Hence, the stacking faults considered in the (110) planes will be studied by means of both a classical unpolarizable Born model and by a simple polarizable shell model.
In the latter case, the study of the polarization energy behaviour versus the stacking fault relaxation is possible.

2. Stacking fault energy calculations. $-2.1 \mathrm{UN}^{-}$ POLARIZABLE BORN MODEL. - Interaction energy, $U_{\mathrm{ij}}$, between two ions $i$ and $j$ may be written [3] :

$$
\begin{aligned}
& U_{\mathrm{ij}}=Z_{\mathrm{i}} Z_{\mathrm{j}} e^{2} R_{\mathrm{ij}}-C_{\mathrm{ij}}^{(6)} R_{\mathrm{ij}}^{-6}-C_{\mathrm{ij}}^{(8)} R_{\mathrm{ij}}^{-8}+ \\
&+b b_{\mathrm{i}} b_{\mathrm{j}} \exp \left(-R_{\mathrm{ij}} / \rho\right) .
\end{aligned}
$$

The different terms of this expression introduced by Benson and Dempsay [3] for cohesive and surface energy calculations are respectively:

- Madelung energy, dipole-dipole and dipolequadrupole Van der Waals terms and the repulsion energy.

The electronic term is obtained by means of a classical method of summation of the interactions between planes [1,2].

The repulsion term is obtained by using the short range potential proposed by Benson and Dempsay [3]. The short range potential used between $\mathrm{F}^{-} \mathrm{F}^{-}$anions is illustrated in figure 1.

The geometry of the stacking faults considered in the different crystallographic planes has been described in a previous work [4].

Results of the calculations are listed in the following table (Table I). 
TABLE I

Results obtained with the unpolarizable Born model. $\left(\mu_{\mathrm{s}}=0.41 \times 10^{11} \mathrm{~Pa}\right)$ Energies $E_{\mathrm{F} 1}$ and $E_{\mathrm{F} 2}$ are in $\mu_{\mathrm{s}} b$ units.

$\begin{array}{ccc}\text { Burger vectors } & E_{\mathrm{F} 1}\left(10^{-3} \mu_{\mathrm{s}} \mathrm{b}\right) & E_{\mathrm{F} 2}\left(10^{-3} \mu_{\mathrm{s}} \mathrm{b}\right) \\ 1 / 4<\overline{1} 10>(110) & 24 & - \\ 1 / 2<100>(110) & 77.8 & 120 \\ 1 / 4<1 \overline{1} 2>(110) & 85 & 250 \\ 1 / 6<\overline{1} 12>(111) & 64.5 & 140 \\ 1 / 6<\overline{1} 12>(111) & & \\ + \text { synchro-shear } & 7.9 & 42 \\ 1 / 2<010>(100) & 42.4 & 87\end{array}$

$E_{\mathrm{F} 1}$ takes into account the electronic polarization by dividing the Madelung energy by the high frequency dielectric constant $\varepsilon_{\infty}=2.05$.

$E_{\mathrm{F} 2}$ is obtained assuming the electronic polarization negligeable when the stacking fault is relaxed.

These assumptions will be discussed latter.

2.2 Polarizable shell MODel. - Only the (110) planes will be dealt with in this paragraph.

In order to refine the S. F. E. calculations, both the ionic and electronic polarization must be estimated. In such neutral planes as (110) planes, the ionic polarizability may be improved when a stacking fault plane distortion is permitted. This method leads to a very weak dissociation of the stacking fault planes in both anionic plane and cationic plane [5].

The electronic polarization may be calculated by different ways. When the point polarizable ion model is used (P. P. I.), some wellknown difficulties arise $[6,7]$.

The shell model developped by Dick and Overhauser seems a more appropriate method. The electronic polarization can be caused by both the electric field due to breakdown of crystal symmetry and by the relative motion of near neighbors, i. e., the short range forces. In the shell model, the outer electrons of an ion, are predominantly responsible for both the polarizability and the repulsion due to the shell overlap.

In this paragraph, the cohesive properties of the crystal are therefore described by means of a polarizable shell model. A shell model has been developped in $\mathrm{CaF}_{2}$ by Axe [9], and more recently by Catlow and Norgett [10, 11].

The energy function involved in such a calculation may be written according to the expression :

$$
\begin{aligned}
E_{\mathrm{T}}=E_{\mathrm{m}} & +\sum_{\mathrm{ij}} \varphi_{\mathrm{ss}}\left(r_{\mathrm{ij}}^{\mathrm{eff}}\right)-\sum_{\mathrm{i}} \mathbf{E}_{\mathrm{i}} \cdot \boldsymbol{\mu}_{\mathrm{i}}-\sum_{\mathrm{ij}} \times \\
& \times \frac{3\left(\boldsymbol{\mu}_{\mathrm{i}} \cdot \mathbf{r}_{\mathrm{ij}}\right) \cdot\left(\boldsymbol{\mu}_{\mathbf{j}} \cdot \mathbf{r}_{\mathrm{ij}}\right)-r_{\mathrm{ij}}^{2} \cdot \boldsymbol{\mu}_{\mathrm{i}} \cdot \boldsymbol{\mu}_{\mathrm{j}}}{r_{\mathrm{ij}}^{5}}+\sum_{\mathrm{i}} \frac{\mu_{\mathrm{i}}^{2}}{\alpha_{0}^{i}}
\end{aligned}
$$

$E_{\mathrm{m}}$ is the Madelung contribution which has been described by Fontaine [1]. $\varphi_{\text {ss }}\left(r_{i j}^{\text {eff }}\right)$ represents the repulsive interaction which exclusively acts through the close electronic shell of ions.
In this calculation, two short range $\mathrm{F}^{-} \mathrm{F}^{-}$potentials derived from the shell model in $\mathrm{CaF}_{2}$ [9] have been used :

- Born Mayer potential supplemented by a Van der Waals term :

$$
V\left(r_{--}\right)=A_{--} \exp -\left(r_{--} / \rho_{1}\right)-C r_{--}^{\sim 6}
$$

- Morse potential :

$V\left(r_{--}\right)=D\left[\left\{1-\exp -\left(\beta\left(r_{--}-r_{\mathrm{e}}\right)\right)\right\}^{2}-1\right]$

Anion-cation interaction is taken as :

$$
V\left(r_{+-}\right)=A_{+-} \exp -\left(r_{+-} / \rho_{2}\right) \text {. }
$$

Those potentials are illustrated in figure 1 .

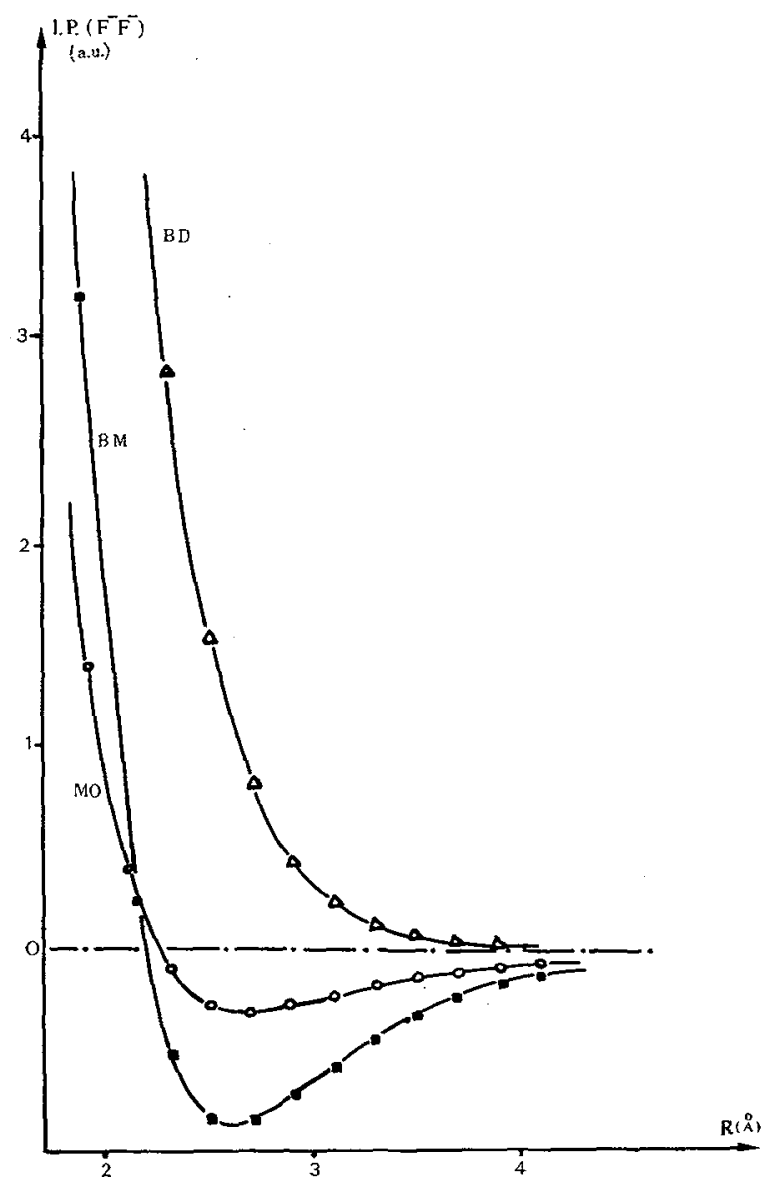

FIG. 1. - Short range potentials used between $\mathrm{F}^{-} \mathbf{F}^{-}$anions. $B D$ : Benson and Dempsay classical exponential form (expression 1). BM : Born Mayer potential derived from the shell model in $\mathrm{CaF}_{2}$ by Catlow and Norgett [6] (expression 3). MO : Morse potential derived from the shell model in $\mathrm{CaF}_{2}$ by Catlow and Norgett [6] (expression 4). The interionic potential, in arbitrary units, is plotted versus the ion separation in $\AA$.

The shell-shell separation between two ions is connected to the dipole moment by a linear dependence and becomes therefore the effective separation which is written as [10] :

$$
\mathbf{r}_{\mathrm{ij}}^{\mathrm{eff}}=\mathbf{r}_{\mathbf{i j}}+\frac{\boldsymbol{\mu}_{\mathrm{i}}}{Q_{\mathrm{i}}}-\frac{\boldsymbol{\mu}_{\mathbf{j}}}{Q_{\mathrm{j}}}
$$


$Q_{\mathrm{i}}$ and $Q_{\mathrm{j}}$ are the shell parameter which have a charge dimension. The computation has been done in the $Q$ range : 1.84 to 3 ;

$\left|\mathbf{r}_{\mathbf{i j}}\right|$ is the distance between the ion cores;

$\left|\mu_{\mathrm{i}} / Q_{\mathrm{i}}\right|$ is the displacement of the shell with respect to the core.

In the term $\sum_{i} \mathbf{E}_{\mathbf{i}} \cdot \boldsymbol{\mu}_{\mathrm{i}}, \mathbf{E}_{\mathbf{i}}$ is the electric field resulting from the crystal symmetry breakdown due to monopoles only. The polarizing field components $E_{x}, E_{y}, E_{z}$, are calculated from the derivatives of the coulombic potential created by a charge plane [1].

The 4th and 5th terms are respectively the dipoledipole interactions and the self energy of the string linking the shell and the core of the ion $\left(\alpha_{0}^{i}\right.$ is the free ion polarizability).

As a consequence of the effective shell-shell separation dependence in $\boldsymbol{\mu}$, the polarization energy interferes with both the short range forces and the last three terms. In this calculation, only the anions are supposed to be polarizable. A stacking fault being a planar defect, it is assumed that all the anions in the vicinity of the stacking fault plane, in $\mathrm{CaF}_{2}$, have the same absolute value of the dipole moment. Close to the stacking fault plane, the two ionic planes have respectively dipole moments $\boldsymbol{\mu}$ and $-\boldsymbol{\mu}\left(\boldsymbol{\mu}_{\mathrm{i}}=-\boldsymbol{\mu}_{\mathrm{j}}\right)$.

The computation parameters are the dilatation $\varepsilon_{z}$, between the stacking fault planes and the dipole moment components. The absolute minimum with respect to these parameters is then the S.F.E. of the relaxed defect.

2.3 Results. - The results obtained are listed in the table II. The influence of the polarization energy

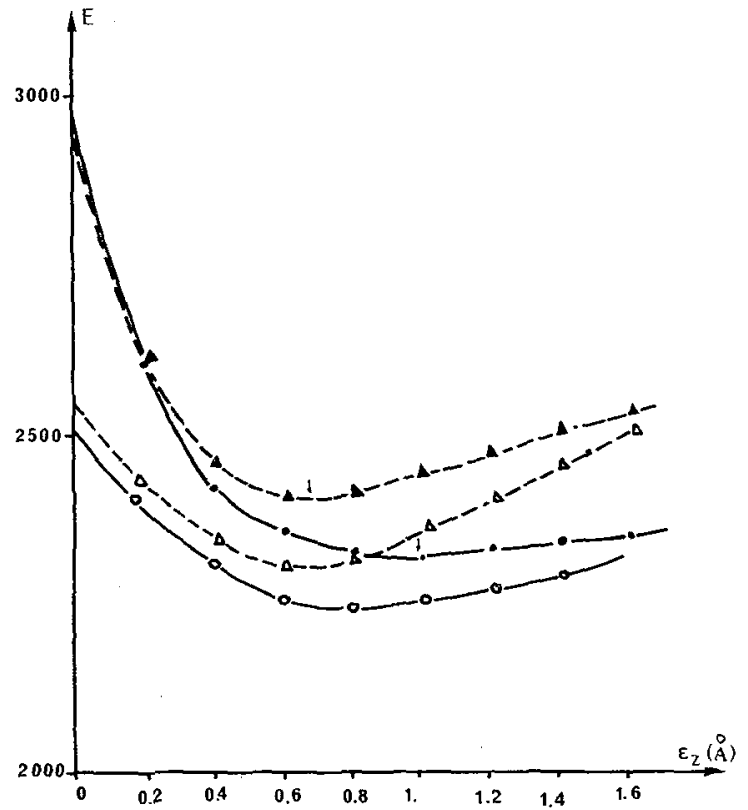

FIG. 2. - Minimization of the S. F. E. versus the relaxation $\varepsilon_{z}$, for $b=a / 2(100)$, in $\mathrm{m}$. joules $/ \mathrm{m}^{2}$. Results obtained when the electronic polarization is neglected. $-\mathrm{O}-\triangle-$ Results obtained when the electronic polarization is taken into account. - Born Mayer potential. . . . . . . Morse potential. is illustrated through the example of the displacement vector $\mathbf{b}=a / 2(100)$, in figures 2 and 3 .

\section{TABLE II}

Different energy components of the S.F.E. obtained with the Born Mayer short range potential. The results are in $\mathrm{m}$.joules $/ \mathrm{m}^{2}$.
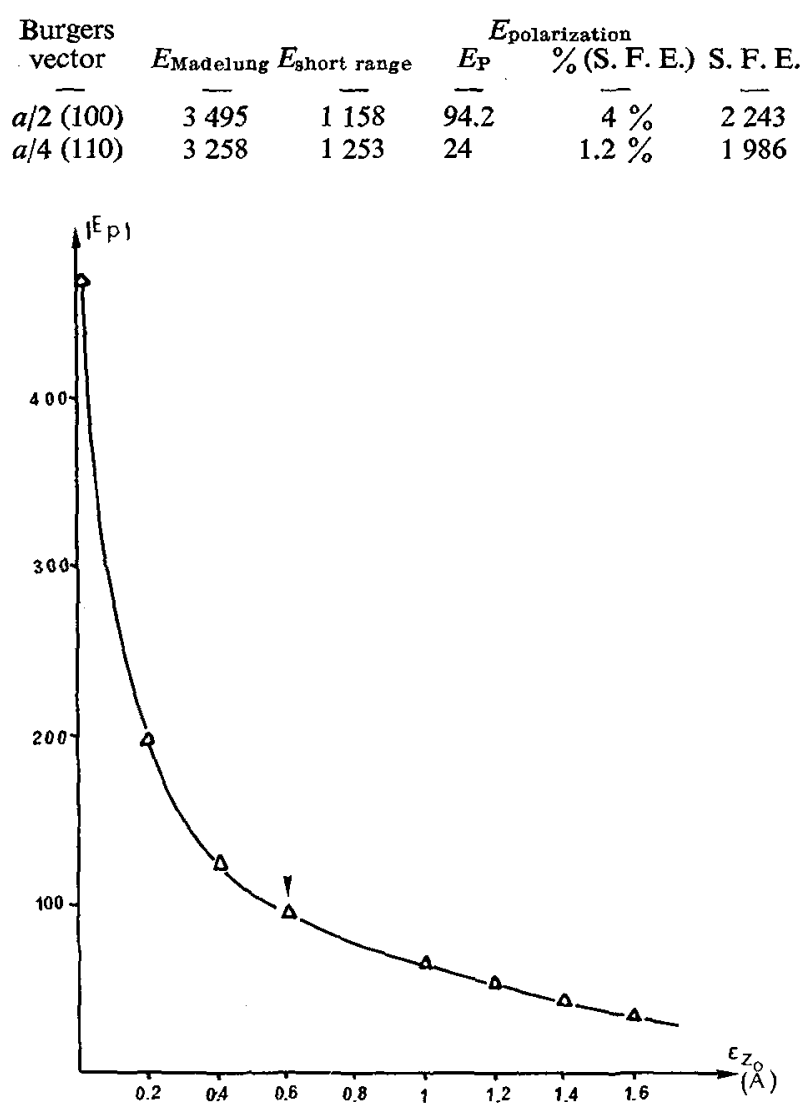

Fig. 3. - Electronic polarization energy variation versus $\boldsymbol{\varepsilon}_{\mathbf{z}}$, for $\mathbf{b}=a / 2(100)$. The arrow indicates the equilibrium relaxation of the stacking fault. The results are in $\mathrm{m} . \mathrm{J} / \mathrm{m}^{2}$.

3. Discussion. - In such computations as S. F. E. calculations, an interesting point is the polarization energy behaviour when the defect is relaxed or not.

The polarization contribution to those results is pointed out by means of the difference between the two functions energy, respectively $E\left(\varepsilon_{z}, \mu\right)$ and $E\left(\varepsilon_{\mathrm{z}}, \boldsymbol{\mu}=0\right)$.

This study, using a simple shell model, shows that the electronic polarization is always weak when the defect is relaxed. The order of magnitude is $5 \%$ of the S. F.E. When the defect is not relaxed, it may be larger, as much as $20 \%$ of the S. F. E. Hence, the method which represents the electronic polarization by dividing the Madelung energy by the high frequency dielectric constant $\varepsilon_{\infty}\left(\varepsilon_{\infty}=2.05\right.$ in $\left.\mathrm{CaF}_{2}\right)$ is erroneous and may leads to a strong underestimate of the results.

Owing to the small polarization term, the difference with the results obtained by the classical unpolarizable Born model, is not important (5-10\%) (Table III). 


\section{TABLE III}

S. F. E. obtained by different methods for $\mathbf{b}=a / 4$ (110) (results are in $\mathrm{m}$.joules $\left./ \mathrm{m}^{2}\right)$; (BM : Born MayerMO : Morse).

\begin{tabular}{cccccc} 
Born & $\begin{array}{c}\text { shell model } \\
(\mu=0)\end{array}$ & \multicolumn{2}{c}{$\begin{array}{c}\text { shell model } \\
(\mu \neq 0)\end{array}$} \\
- & \multicolumn{2}{c}{-} & \multicolumn{2}{c}{-} & \\
& BM & \multicolumn{3}{c}{ BM } & \\
2121 & 2010 & MO & 1986 & MO \\
& & 2058 & & 2013
\end{tabular}

The S. F. E. calculated in $\mathrm{CaF}_{2}$ are generally high, then an attempt to estimate a dislocation splitting width would be suspect.

4. Conclusion. - A S. F. E. energy computation using a simple shell model is given. The results are compared to those obtained using a classical unpolarizable Born model.

When the defect is relaxed, the polarization is always weak, $5 \%$ of the S. F. E. The resulting S. F. E. do not show much difference with the classical method.

The S.F. E. $s_{s}$ are generally high and cannot be connected to dislocation splitting.

\section{References}

[1] Fontaine, G. J., J. Phys. \& Chem. Solids 28 (1967) 2199.

[2] Fontanne, G. J., J. Phys. \& Chem. Solids 28 (1967) 2553.

[3] Benson, G. C. and Dempsay, E., Proc. R. Soc. 266A (1962) 344.

[4] Gaboriaud, R. J., Boisson, M. and Grilhe, J., J. Phys. $C$ : Sol. Stat. Phys. 8 (1975) 3499.

[5] Gaboriaud, R. J., Boisson, M. and Grilhe, J., J. Phys. Chem. Sol., in press.

[6] Catlow, C. R. A., Phil. Thesis, Oxford, 1974.

[7] Faux, I. D., J. Phys. C : Sol. Stat. Phys. 4 (1971) L211.
[8] Dick, Jr. B. J. and Overhauser, A. W., Phys. Rev. 112 (1958) 90.

[9] Axe, J. D., Phys. Rev. 139 (1965) A1215.

[10] Catlow, C. R. A. and Norgett, M. J., J. Phys. C: Sol. Stat. Phys. 6 (1973) 1325.

[11] Catlow, C. R. A. and Norgett, M. J., J. Physique Colloq. 34 (1975) C9-45.

[12] Dienes, G. J., Welch, D. O., Fisher, C. R., HatCher, R. D., Lazareth, O., SamberG, M., Phys. Rev. 11 (1975) 3060. 